\title{
NIR-to-visible and NIR-to-NIR upconversion in lanthanide doped nanocrystalline GdOF with trigonal structure
}

\author{
T. Passuello ${ }^{\text {a }}$, F. Piccinelli ${ }^{\text {a }}$, M. Pedroni ${ }^{\text {a }}$, S. Polizzi ${ }^{\text {b }}$, F. Mangiarini ${ }^{c}$, F. Vetrone $^{\text {d }}$, M. Bettinelli $^{\text {a }}$, A. Speghini $^{\text {a, }}{ }^{*}$ \\ ${ }^{a}$ Laboratorio di Chimica dello Stato Solido, DB, Università di Verona and INSTM, UdR Verona, Ca' Vignal, Strada Le Grazie 15, I-37134 Verona, Italy \\ b Dipartimento di Scienze Molecolari e Nanosistemi, Università Ca' Foscari Venezia and INSTM, UdR Venezia, Via Torino 155/b, 30172 Venezia-Mestre, Italy \\ ${ }^{\mathrm{c}}$ Department of Chemistry and Biochemistry, Concordia University, 7141 Sherbrooke Street West, Montreal, Canada QC H4B 1R6 \\ ${ }^{\mathrm{d}}$ Institut National de la Recherche Scientifique - Énergie, Matériaux et Télécommunications, Université du Québec, Varennes, Canada QC J3X 1S2
}

\section{A R T I C L E I N F O}

\section{Article history:}

Received 27 January 2011

Accepted 22 February 2011

Available online 26 March 2011

\section{Keywords:}

Lanthanide

Upconversion

Nanocrystalline materials

\begin{abstract}
A B S T R A C T
Codoped $\mathrm{Er}^{3+} / \mathrm{Yb}^{3+}, \mathrm{Tm}^{3+} / \mathrm{Yb}^{3+}, \mathrm{Ho}^{3+} / \mathrm{Yb}^{3+}$ and triply doped $\mathrm{Er}^{3+} / \mathrm{Tm}^{3+} / \mathrm{Yb}^{3+}$ gadolinium oxyfluoride nanoparticles were prepared in aqueous solution by a simple coprecipitation method and a suitable heat treatment at $500{ }^{\circ} \mathrm{C}$. From the experimental X-Ray powder diffraction patterns, a Rietveld analysis was carried out and it was determined that the nanoparticles are single phase trigonal GdOF. Electron microscopy images show that the average particle size is approximately $25 \mathrm{~nm}$, even though a certain degree of agglomeration is evidenced. The spectroscopic properties of the lanthanide doped nanoparticles are investigated in terms of emission spectra. For proper lanthanide concentrations, the nanoparticles show visible upconversion upon excitation at $980 \mathrm{~nm}$, making them useful as luminescent nanomaterials for photonic applications.
\end{abstract}

(c) 2011 Elsevier B.V. All rights reserved.

\section{Introduction}

Significant efforts have been undertaken in the recent past to develop new nanostructured lanthanide doped luminescent materials for their possible use in cutting-edge photonic applications $[1,2]$. In particular, these materials have been demonstrated to be of paramount importance in light emitting diodes (LED and organic LED) $[3,4]$, solar energy converters [5,6] and as materials for biomedical applications, in particular in the field of optical imaging $[7,8]$. Recent research activities have been devoted to investigations on new lanthanide doped nanocrystalline hosts showing strong luminescence [9]. The preparation method of the materials is also of great importance as it should be easy, fast and environmentally friendly.

Lanthanide doped luminescent fluoride nanocrystalline materials are currently being intensively investigated, due to their low phonon energy cut off and in turn to their low probability of the multiphonon deexcitation pathways $[10,11]$. Oxyfluorides have been also studied as hosts that can easily accommodate luminescent lanthanide ions as dopants. Few papers have appeared in the literature reporting the synthesis and spectroscopic properties of lanthanide doped based oxyfluorides. For instance, bulk samples of $\mathrm{Eu}^{3+}$ or $\mathrm{Tb}^{3+}$ doped lanthanum, gadolinium and yttrium oxyfluorides [12,13], thin films of $\mathrm{Eu}^{3+}$ doped LaOF oxyfluoride [14] and $\mathrm{Eu}^{3+}$ doped gadolinium fluoride nanoparticles embedded in a silica

\footnotetext{
* Corresponding author.

E-mail address: adolfo.speghini@univr.it (A. Speghini).
}

film [15] have been recently studied. Moreover, cubic gadolinium oxyfluoride nanoparticles doped with lanthanide ions have also been prepared starting from trifluoroacetate precursors in highboiling solvents and their luminescence properties have been investigated [16]. Very recently, a paper on the upconversion (UC) properties of lanthanide doped $\mathrm{Er}^{3+} / \mathrm{Tm}^{3+} / \mathrm{Yb}^{3+} \mathrm{Gd}_{4} \mathrm{O}_{3} \mathrm{~F}_{6}$ nanoparticles has been published [17]. Aside from these few cases, to the best of our knowledge, no other papers have been appeared in the literature concerning nanocrystalline upconverting GdOF samples.

For these reasons, we found it interesting to prepare $\mathrm{Er}^{3+} / \mathrm{Yb}^{3+}$ $\mathrm{Ho}^{3+} / \mathrm{Yb}^{3+}, \mathrm{Tm}^{3+} / \mathrm{Yb}^{3+}$ and $\mathrm{Er}^{3+} / \mathrm{Tm}^{3+} / \mathrm{Yb}^{3+}$ doped GdOF nanocrystalline samples with a trigonal structure and to investigate the structural and spectroscopic properties, in particular the upconversion emission. The codoped nanocrystalline samples have been prepared via a facile coprecipitation technique using water as the solvent and inexpensive metal and fluorine precursors. The structural features, such as lattice parameters and average particle size, have been investigated using a Rietveld refinement while the morphological analysis has been carried out using Transmission Electron Microscopy (TEM). Laser excited Stokes and UC luminescence of the lanthanide doped materials have been measured and analyzed.

\section{Experiment}

\subsection{Synthesis}

Lanthanide doped gadolinium oxyfluoride nanocrystalline samples of composition $\mathrm{Gd}_{0.89} \mathrm{Ln}_{0.01} \mathrm{Yb}_{0.1} \mathrm{OF}(\mathrm{Ln}=\mathrm{Er}$, Ho and $\mathrm{Tm}$ ) and 
$\mathrm{Gd}_{(0.98-x)} \mathrm{Er}_{0.01} \mathrm{Tm}_{0.01} \mathrm{Yb}_{x} \mathrm{OF}(x=0.01,0.10)$ were prepared by a simple coprecipitation procedure as follows. Reagent grade metal nitrates $\left(\mathrm{Gd}\left(\mathrm{NO}_{3}\right)_{3} \cdot 6 \mathrm{H}_{2} \mathrm{O}\right.$, Aldrich, 99.999\%, $\mathrm{Er}\left(\mathrm{NO}_{3}\right)_{3} \cdot 6 \mathrm{H}_{2} \mathrm{O}, \mathrm{Al}-$ drich, 99.9\%, $\mathrm{Tm}\left(\mathrm{NO}_{3}\right)_{3} \cdot 6 \mathrm{H}_{2} \mathrm{O}$, Aldrich, 99.999\%, $\mathrm{Ho}\left(\mathrm{NO}_{3}\right)_{3} \cdot 6 \mathrm{H}_{2} \mathrm{O}$, Aldrich, 99.999\%, $\mathrm{Yb}\left(\mathrm{NO}_{3}\right)_{3} \cdot 6 \mathrm{H}_{2} \mathrm{O}$, Aldrich, 99.999\%) and $\mathrm{NH}_{4} \mathrm{~F}(\mathrm{Al}-$ drich, $99.9 \%$ ) were used as starting reagents. $0.886 \mathrm{mmol}$ of gadolinium nitrate were dissolved in $25 \mathrm{ml}$ of water together with a stoichiometric amount of the other metal nitrates. A proper amount of an aqueous solution of ammonium fluoride $3.98 \mathrm{mM}$ was then slowly mixed to the metal nitrate one, under stirring, in order to maintain a 1:1 metal-to-fluoride molar ratio. The $\mathrm{pH}$ of the solution was then adjusted to 10 by adding drops of $1.0 \mathrm{M}$ $\mathrm{NaOH}$ solution and the resulting solution was then heat treated at $80^{\circ} \mathrm{C}$ for $2 \mathrm{~h}$ under stirring. The precipitates were filtered, thoroughly rinsed with copious amounts of deionized water in order to remove the residues of the nitrate and ammonium ions. Subsequently, the powders were dried at $90{ }^{\circ} \mathrm{C}$ overnight and then heat treated in air at $500{ }^{\circ} \mathrm{C}$ for $5 \mathrm{~h}$.

\subsection{X-Ray powder diffraction}

X-Ray powder diffraction (XRPD) patterns were measured with a Thermo ARL X́TRA powder diffractometer, operating in

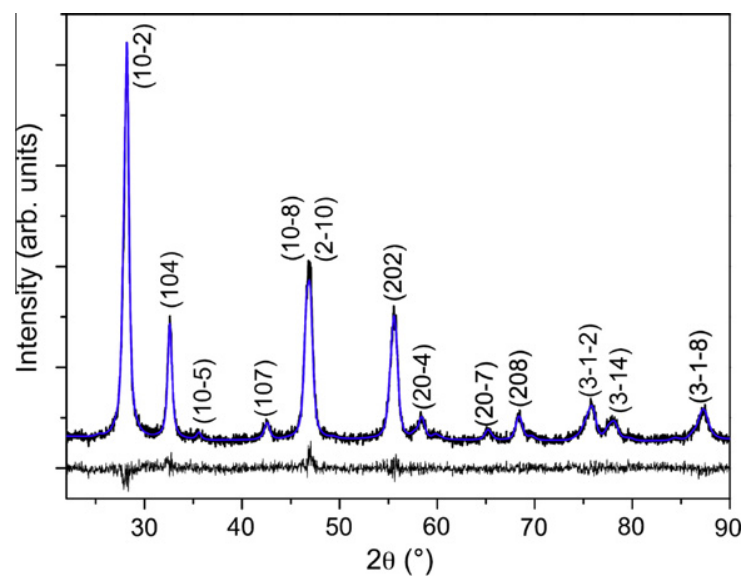

Fig. 1. X-Ray powder diffraction patterns for the $\mathrm{Tm}^{3+} / \mathrm{Yb}^{3+}$ doped GdOF sample: measured (black line) and calculated by a Rietveld refinement (blue line). Lower trace: residuals between the measured and calculated patterns. (For interpretation of the references to color in this figure legend, the reader is referred to the web version of this article.)
Bragg-Brentano geometry, equipped with a $\mathrm{Cu}$-anode X-ray source $(\mathrm{K} \alpha, \lambda=1.5418 \AA$ ) and using a Peltier $\mathrm{Si}(\mathrm{Li})$ cooled solid state detector. The spectra were collected with a scan rate of $0.003 \%$, time of exposure $9.0 \mathrm{~s} / \mathrm{step}$ and $2 \theta$ range of $24^{\circ}-90^{\circ}$. The phase identification was performed with the PDF-4+2008 database provided by the International Centre for Diffraction Data (ICDD). The powder samples were ground in a mortar and then deposited in a low-background sample stage for the XRPD pattern collection.

\subsection{Transmission Electron Microscopy}

Transmission Electron Microscopy (TEM) and high resolution TEM (HRTEM) images were taken with a JEOL 3010 high resolution electron microscope $(0.17 \mathrm{~nm}$ point-to-point), operating at $300 \mathrm{kV}$, equipped with a Gatan slow-scan CCD camera (model 794) and an Oxford Instrument EDS microanalysis detector (Model 6636). The powder was dispersed in a toluene solution and deposited on a holey carbon film.

\subsection{Luminescence}

Luminescence spectra were measured using a diode laser at $980 \mathrm{~nm}$ as the source (Coherent 6-pin fiber-coupled F6 series $980 \mathrm{~nm}$ laser diode), coupled to a $100 \mu \mathrm{m}$ (core) fiber or at $488 \mathrm{~nm}$ using an Argon laser (Coherent Sabre Innova). Emission radiation was detected in both cases by a thermoelectricallycooled Hamamatsu R943-02 photomultiplier tube. The signal was processed with a SR Standard Research Systems Preamplifier and recorded using the Standard SR465 software data acquisition/analyzer system.

\section{Results and discussion}

\subsection{Structural and morphological characterization}

The XRPD powder patterns of all the synthesized compounds clearly show the presence of a single trigonal crystal phase with space group $R-3 m$ (space group no. 166) according with the reference card no. 00-050-0569 of the PDF-4+2008 database. A Rietveld refinement $[18,19]$ exploiting the trigonal structural model proposed by Hölsa et al. [20] for SmOF, was carried out on the powder pattern for the $\mathrm{Tm}^{3+} / \mathrm{Yb}^{3+}$ codoped oxyfluoride sample (see Fig. 1). In this compound, of GdOF composition, all the ions $\left(\mathrm{Gd}^{3+}, \mathrm{O}^{2-}\right.$ and $\left.\mathrm{F}^{-}\right)$occupy the same number of symmetrically equivalent positions with the same $C_{3 v}$ site symmetry. In addition, the cell lattice parameters and the average crystallite size were
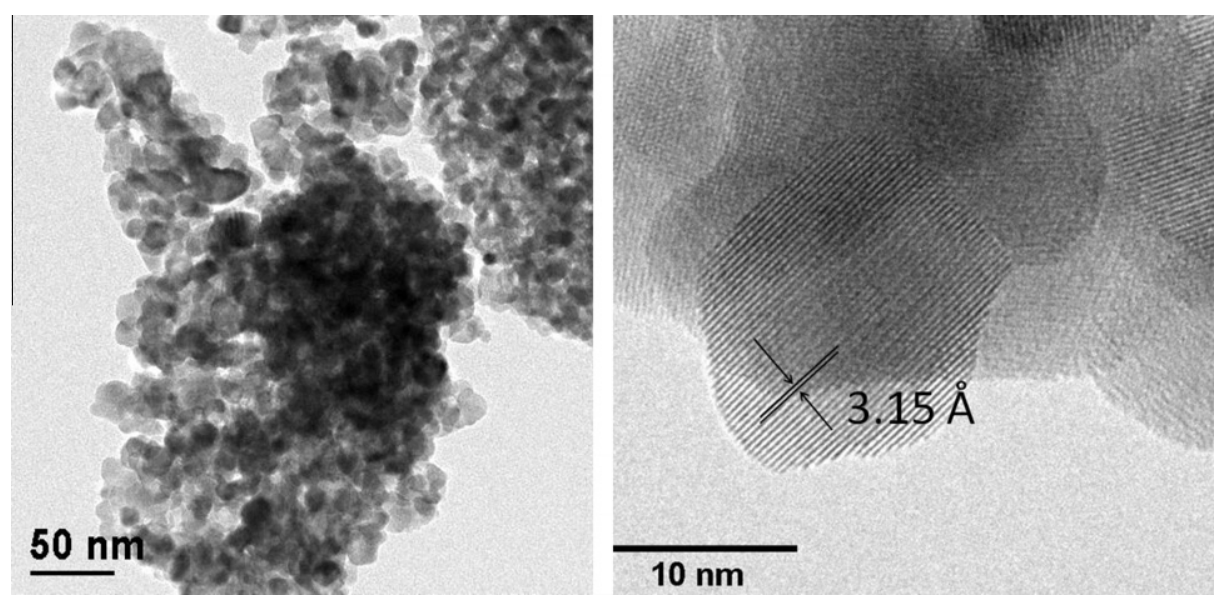

Fig. 2. Representative examples of TEM and HRTEM images of the GdOF nanoparticles. The lattice planes refers to the (1 $0-2)$ Miller indexes. 
calculated. In particular, the average crystallite size resulted to be $25(1) \mathrm{nm}$, the cell parameters $a=3.860$ (1) $\AA, c=19.154(3) \AA$, and the cell volume is $247.15(1) \AA^{3}$. In comparison with the cell volume of undoped GdOF (249.11 $\AA^{3}$, reference card n. 00-050-0569 of the PDF-4+2008 database) a slight contraction of the unit cell is observed, due to the smaller ionic radius of the dopant ions $\left(\mathrm{Yb}^{3+}\right.$, ionic radius of $1.12 \AA$ and $\mathrm{Tm}^{3+}$, ionic radius of $1.18 \AA$, in eight-fold coordination [21]) substituting for the larger $\mathrm{Gd}^{3+}$ ion (ionic radius $1.20 \AA$ in eight-fold coordination [21]).

TEM and HRTEM images (see Fig. 2) show that the nanoparticles have a roundish shape and an average size around $25 \mathrm{~nm}$, in agreement with the results of the Rietveld analysis of the XRPD patterns.
A certain degree of aggregation of the nanoparticles can be noted from the TEM images.

\subsection{Luminescence properties}

The Stokes and upconversion spectra of the $\mathrm{Er}^{3+} / \mathrm{Yb}^{3+} \mathrm{GdOF}$ codoped sample, shown in Fig. 3, highlight the characteristic emission bands due to $4 f-4 f$ transitions of the $\mathrm{Er}^{3+}$ ions. The Stokes spectrum has been measured upon laser excitation at $488.0 \mathrm{~nm}$, which directly populates the ${ }^{4} \mathrm{~F}_{7 / 2}$ of the $\mathrm{Er}^{3+}$ ions. As a consequence, the ${ }^{2} \mathrm{H}_{11 / 2}$ and ${ }^{4} \mathrm{~S}_{3 / 2}$ levels are populated by non-radiative multiphonon relaxation (MPR) and emissions from these levels are observed in

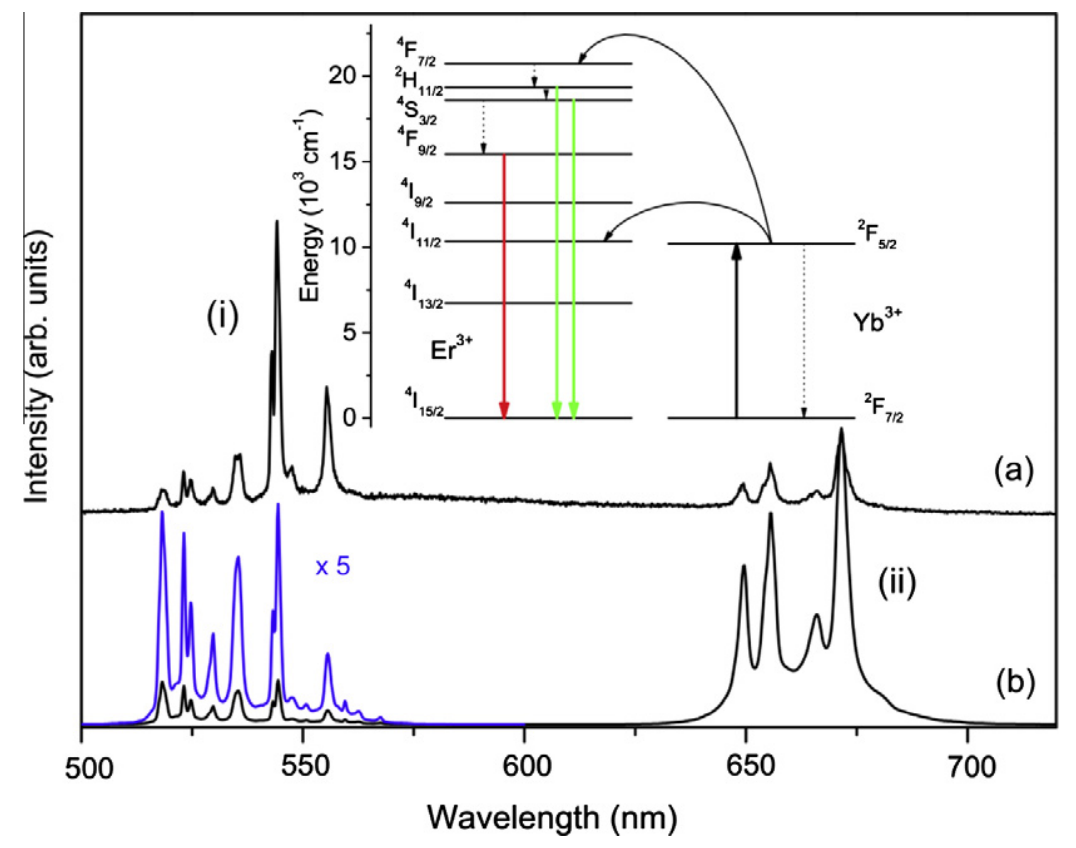

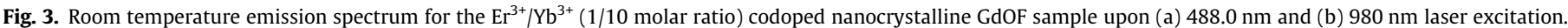
Transition assignments: (i): $\left({ }^{2} \mathrm{H}_{11 / 2},{ }^{4} \mathrm{~S}_{3 / 2}\right) \rightarrow{ }^{4} \mathrm{I}_{15 / 2}$; (ii): ${ }^{4} \mathrm{~F}_{9 / 2} \rightarrow{ }^{4} \mathrm{I}_{15 / 2}$.

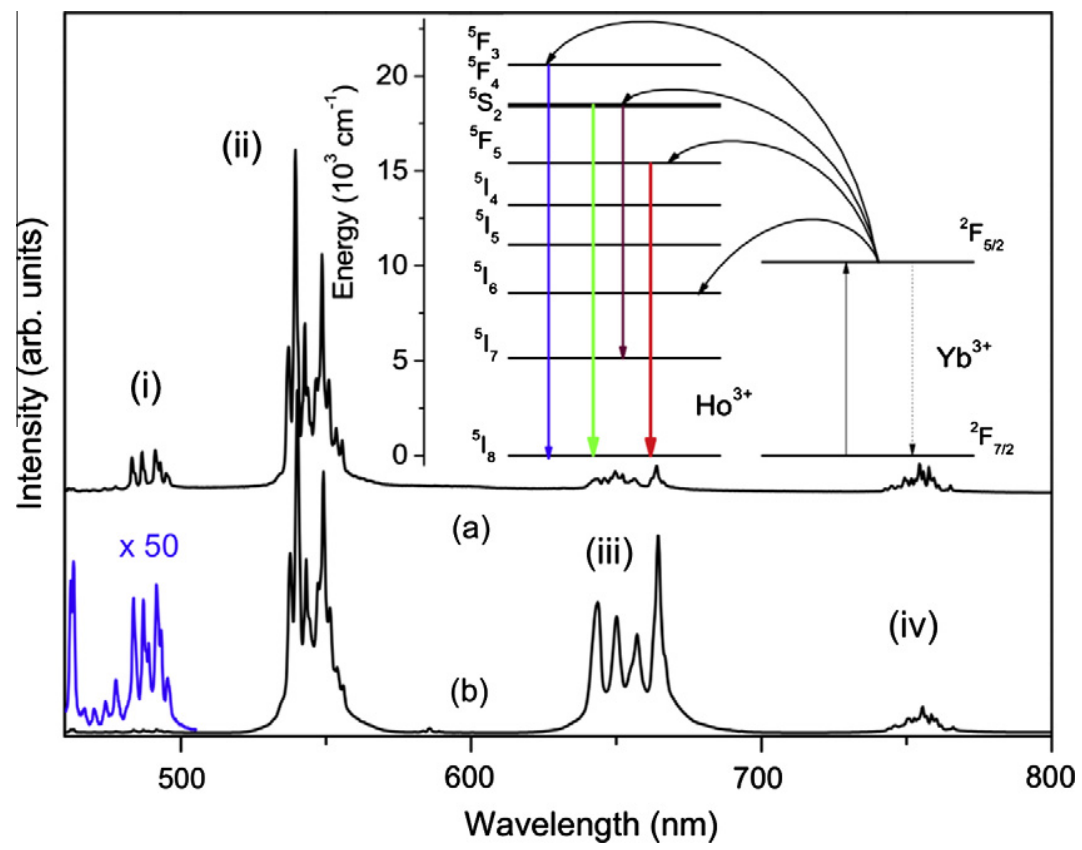

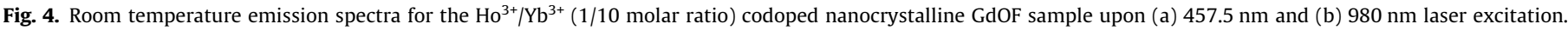
Transition assignments: (i): ${ }^{5} \mathrm{~F}_{3} \rightarrow{ }^{5} \mathrm{I}_{8}$; (ii) $\left({ }^{5} \mathrm{~S}_{2},{ }^{5} \mathrm{~F}_{4},\right) \rightarrow{ }^{5} \mathrm{I}_{8}$; (iii): ${ }^{5} \mathrm{~F}_{5} \rightarrow{ }^{5} \mathrm{I}_{8}$; (iv) $\left({ }^{5} \mathrm{~S}_{2},{ }^{5} \mathrm{~F}_{4},\right) \rightarrow{ }^{5} \mathrm{I}_{7}$. 


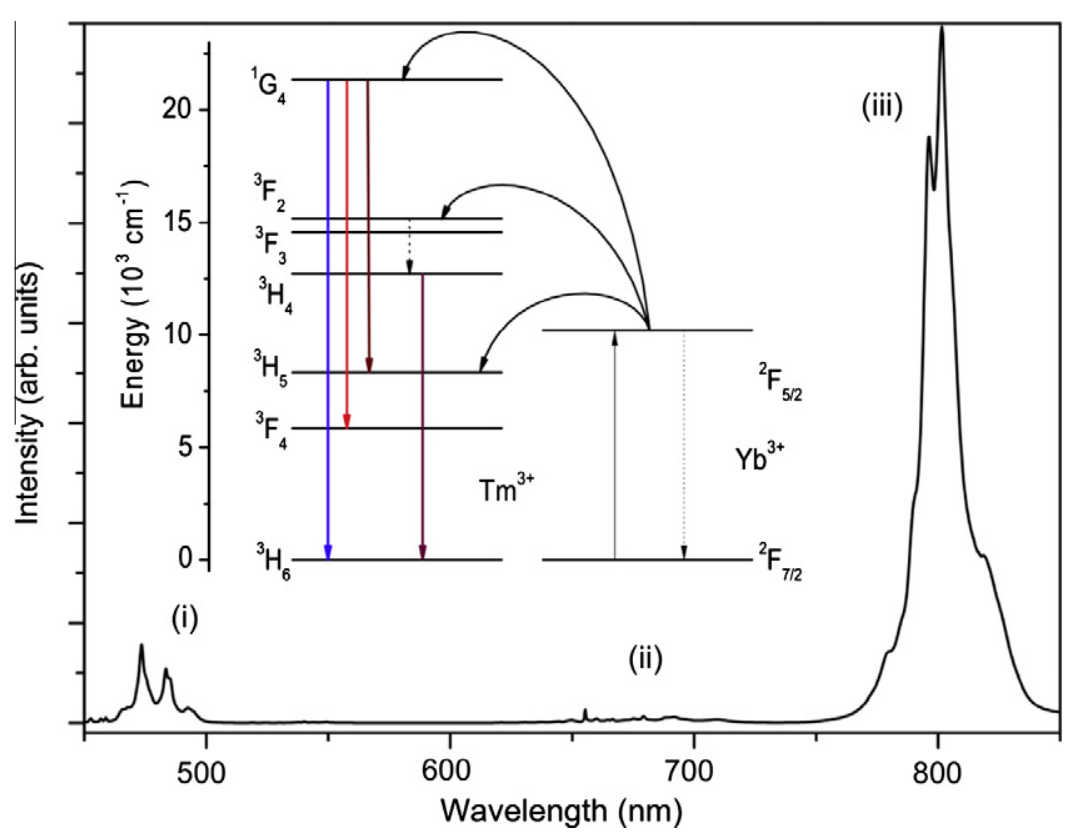

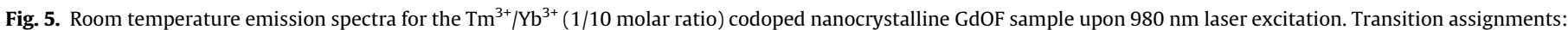
(i): ${ }^{1} \mathrm{G}_{4} \rightarrow{ }^{3} \mathrm{H}_{6}$; (ii): ${ }^{1} \mathrm{G}_{4} \rightarrow{ }^{3} \mathrm{~F}_{4}$; (iii) ${ }^{1} \mathrm{G}_{4} \rightarrow{ }^{3} \mathrm{H}_{5},{ }^{3} \mathrm{H}_{4} \rightarrow{ }^{3} \mathrm{H}_{6}$.

the 520-560 nm range $\left(\left({ }^{2} \mathrm{H}_{11 / 2},{ }^{4} \mathrm{~S}_{3 / 2}\right) \rightarrow{ }^{4} \mathrm{I}_{15 / 2}\right.$ transition $)$. Similarly, the next low lying excited ${ }^{4} \mathrm{~F}_{9 / 2}$ level is in turn populated by MPR processes starting from the ${ }^{4} \mathrm{~S}_{3 / 2}$ level, and it gives rise to emission in the red region $\left({ }^{4} \mathrm{~F}_{9 / 2} \rightarrow{ }^{4} \mathrm{I}_{15 / 2}\right.$ transition, $640-680 \mathrm{~nm}$ range). The ${ }^{2} \mathrm{H}_{11 / 2} \rightarrow{ }^{4} \mathrm{I}_{15 / 2}$ emission bands (observed in the $510-540 \mathrm{~nm}$ range) show higher intensity than the ${ }^{4} \mathrm{~S}_{3 / 2} \rightarrow{ }^{4} \mathrm{I}_{15 / 2}$ ones (observed in the 540-570 nm range) upon $980 \mathrm{~nm}$ laser excitation with respect to $488 \mathrm{~nm}$. Since the ${ }^{2} \mathrm{H}_{11 / 2}$ and ${ }^{4} \mathrm{~S}_{3 / 2}$ levels are separated by a relatively low energy gap (about $750 \mathrm{~cm}^{-1}$ ) and are in thermal equilibrium, this behavior could be explained by the presence of a local heating of the sample, under $980 \mathrm{~nm}$ NIR excitation. This heating will induce a population increase of the ${ }^{2} \mathrm{H}_{11 / 2}$ higher lying level and therefore a stronger emission intensity. This behavior is well-known and it was already observed for other $\mathrm{Yb}^{3+} / \mathrm{Er}^{3+}$ doped nanocrystalline samples [22-24].

The Stark level structure of the emission transitions is clearly evident, indicating that inhomogeneous broadening is not very important in determining the width of the emission bands. This behavior points to a quite ordered environment around the lanthanide ions, similar to that found for $\mathrm{Er}^{3+}$ doped sesquioxides, such as $\mathrm{Y}_{2} \mathrm{O}_{3}, \mathrm{Lu}_{2} \mathrm{O}_{3}$ and $\mathrm{Gd}_{2} \mathrm{O}_{3}$ [25-27] or garnets (i.e. lutetium gallium garnet [28]). On the other hand, this behavior is different from that observed for a $\mathrm{Er}^{3+} / \mathrm{Tm}^{3+} / \mathrm{Yb}^{3+}$ doped gadolinium fluoride nanoparticles of different composition $\left(\mathrm{Gd}_{4} \mathrm{O}_{3} \mathrm{~F}_{6}\right.$, of tetragonal crystal phase), for which very broad emission bands are observed [17]. Therefore, in this latter case, a much higher amount of local disorder is present around the dopant lanthanide ions with respect to the present GdOF samples. The UC spectrum observed upon $980 \mathrm{~nm}$ laser excitation consists of two distinct green and red emission bands similar to those observed in the Stokes spectrum (see Fig. 3). The yellowish emission (see the CIE coordinates, described below) can be easily seen by the naked eye, indicating that quite efficient UC emission has been achieved in the present material. Since the $\mathrm{Yb}^{3+}$ concentration is relatively high $(10 \mathrm{~mol} \%$ with respect to the $\mathrm{Gd}^{3+}$ ions), the UC mechanism can be explained by an energy transfer mechanism (ETU) [29], shown schematically in Fig. 3 (inset).

Upon $457.5 \mathrm{~nm}$ excitation, Stokes emission bands due to $4 f-4 f$ transitions of $\mathrm{Ho}^{3+}$ ions are observed for the $\mathrm{Ho}^{3+} / \mathrm{Yb}^{3+}$ doped GdOF nanocrystalline sample, as shown in Fig. 4. A dominant green emission around $550 \mathrm{~nm}$ is assigned to transitions from the $\left({ }^{5} \mathrm{~F}_{4},{ }^{5} \mathrm{~S}_{2}\right)$ thermalized levels to the ${ }^{5} \mathrm{I}_{8}$ ground state. Much weaker emissions are observed in the red region around $650 \mathrm{~nm}$, due to the ${ }^{5} \mathrm{~F}_{5} \rightarrow{ }^{5} \mathrm{I}_{8}$ transition and between 730 and $780 \mathrm{~nm}$, due to the $\left({ }^{5} \mathrm{~F}_{4},{ }^{5} \mathrm{~S}_{2}\right) \rightarrow{ }^{5} \mathrm{I}_{7}$ transition. A weak emission is also observed in the 480-500 nm region, assigned to the ${ }^{5} \mathrm{~F}_{3} \rightarrow{ }^{5} \mathrm{I}_{8}$ transition. The emission spectrum is similar to that observed for a $\mathrm{Ho}^{3+}$ doped nanocrystalline lutetium gallium garnet sample prepared by a propellant synthesis [28]. As mentioned for the $\mathrm{Er}^{3+} / \mathrm{Yb}^{3+}$ sample, an ETU mechanism is very likely to be present, as schematically shown in Fig. 4 (inset). To the best of our knowledge, this is the first time that $\mathrm{UC}$ of $\mathrm{Ho}^{3+} / \mathrm{Yb}^{3+}$ doped lanthanide based oxyfluorides is reported. Some recent papers reported on the UC of $\mathrm{Ho}^{3+} / \mathrm{Yb}^{3+}$ doped sesquioxide nanoparticles. In particular, Glaspell et al. [30] observed a green UC for $\mathrm{Ho}^{3+} / \mathrm{Yb}^{3+}$ doped monoclinic $\mathrm{Y}_{2} \mathrm{O}_{3}$ nanoparticles prepared by a vapor phase synthesis (of $\mathrm{Y}_{1.88} \mathrm{Ho}_{0.02} \mathrm{Y}$ $\mathrm{b}_{0.10} \mathrm{O}_{2}$ composition). Moreover, very recently, Yang et al. reported an investigation on the spectroscopic properties of a $\mathrm{Ho}^{3+} / \mathrm{Yb}^{3+}$ doped cubic $\mathrm{Lu}_{2} \mathrm{O}_{3}$ nanoparticles and they also observed

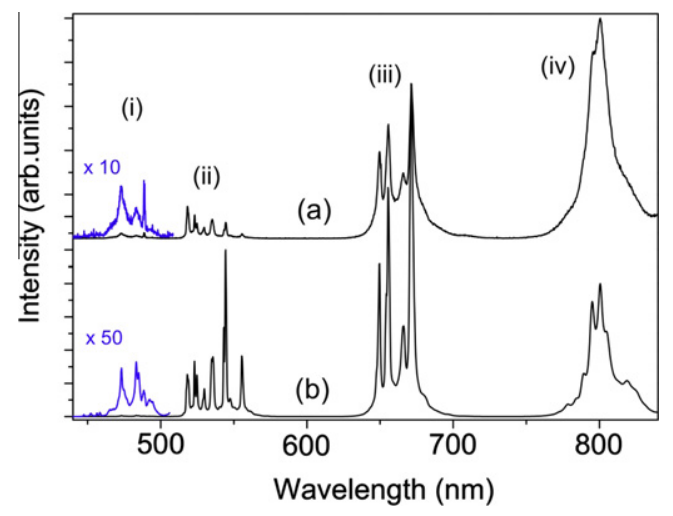

Fig. 6. Room temperature upconversion spectrum for the (a) $1 / 1 / 10$ and (b) $1 / 1 / 1$ molar ratio $\mathrm{Er}^{3+} / \mathrm{Tm}^{3+} / \mathrm{Yb}^{3}$ nanocrystalline codoped GdOF samples upon $980 \mathrm{~nm}$ laser excitation. Transition assignments: (i): ${ }^{1} \mathrm{G}_{4} \rightarrow{ }^{3} \mathrm{H}_{6}\left(\mathrm{Tm}^{3+}\right)$; (ii) $\left({ }^{2} \mathrm{H}_{11 / 2},{ }^{4} \mathrm{~S}_{3 /}\right.$ 2) $\rightarrow{ }^{4} \mathrm{I}_{15 / 2}\left(\mathrm{Er}^{3+}\right)$; (iii): ${ }^{1} \mathrm{G}_{4} \rightarrow{ }^{3} \mathrm{~F}_{4}\left(\mathrm{Tm}^{3+}\right),{ }^{4} \mathrm{~F}_{9 / 2} \rightarrow{ }^{4} \mathrm{I}_{15 / 2}\left(\mathrm{Er}^{3+}\right)$; (iv) ${ }^{1} \mathrm{G}_{4} \rightarrow{ }^{3} \mathrm{H}_{5}\left(\mathrm{Tm}^{3+}\right)$, ${ }^{3} \mathrm{H}_{4} \rightarrow{ }^{3} \mathrm{H}_{6}\left(\mathrm{Tm}^{3+}\right)$. 
a green dominant contribution for the UC [31]. The behavior found for the sesquioxides is different than for the present materials for which an almost white emission is observed for the $\mathrm{Ho}^{3+} / \mathrm{Yb}^{3+}$ doped sample (see CIE coordinates, described below). This behavior is due to a higher red to green emission ratio for the materials under investigation, with respect to the sesquioxide nanocrystalline samples. A possible explanation of this behavior could be found by a detailed study of the evolution of the excited state populations involving the $\left({ }^{5} \mathrm{~F}_{4},{ }^{5} \mathrm{~S}_{2}\right)$ and ${ }^{5} \mathrm{~F}_{5}$ levels of the $\mathrm{Ho}^{3+}$ ions (from which the green and red emission originate), which is beyond the scope of this paper.

The room temperature UC luminescence spectrum of the $\mathrm{Tm}^{3+}$ | $\mathrm{Yb}^{3+}$ doped GdOF sample, shown in Fig. 5, was obtained upon

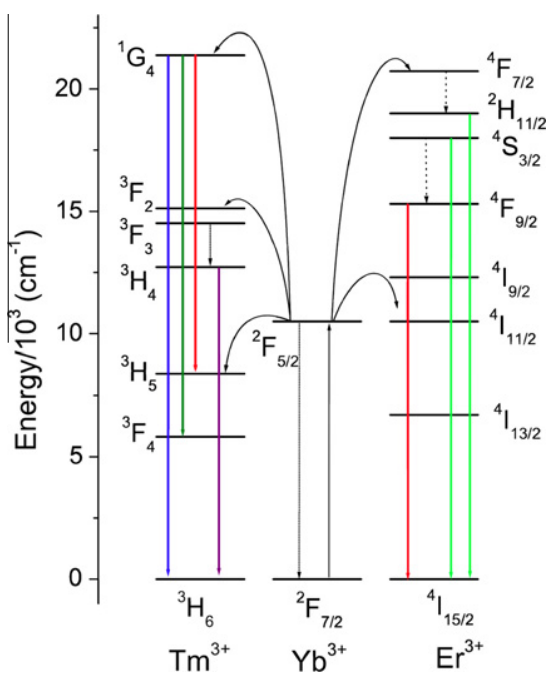

Fig. 7. Schematic representation of the upconversion processes for $\mathrm{Tm}^{3+} / \mathrm{Er}^{3+} / \mathrm{Yb}^{3+}$ systems.
$980 \mathrm{~nm}$ laser excitation. It is interesting to note that the spectrum is dominated by a strong NIR luminescence, around $800 \mathrm{~nm}$, attributed to the overlap of ${ }^{1} \mathrm{G}_{4} \rightarrow{ }^{3} \mathrm{H}_{5}$ and ${ }^{3} \mathrm{H}_{4} \rightarrow{ }^{3} \mathrm{H}_{6}$ transitions of the $\mathrm{Tm}^{3+}$ ions. Much weaker emission is observed in the blue-green region, around $485 \mathrm{~nm}$, which can be assigned to the ${ }^{1} \mathrm{G}_{4} \rightarrow{ }^{3} \mathrm{H}_{6}$ transition of the $\mathrm{Tm}^{3+}$ ions. Moreover, very weak emission in the $620-$ $700 \mathrm{~nm}$ range is due to the ${ }^{1} \mathrm{G}_{4} \rightarrow{ }^{3} \mathrm{~F}_{4}$ transition of the $\mathrm{Tm}^{3+}$ ions. A strong enhancement of the NIR UC emission around $800 \mathrm{~nm}$, with respect to the visible one, upon $980 \mathrm{~nm}$ laser excitation, has been also observed for $\mathrm{Tm}^{3+} / \mathrm{Yb}^{3+}$ doped nanocrystalline fluorides, such as $\mathrm{NaYF}_{4}$ [32,33] and $\mathrm{GdF}_{3}$ [34]. In Fig. 5 (inset) a schematic representation of the expected upconversion processes populating the ${ }^{1} \mathrm{G}_{4}$ level of the $\mathrm{Tm}^{3+}$ ions upon excitation at $980 \mathrm{~nm}$ is proposed.

The emission spectra for the prepared nanocrystalline GdOF samples codoped with $\mathrm{Er}^{3+} / \mathrm{Tm}^{3+} / \mathrm{Yb}^{3+}(1 / 1 / 1$ and $1 / 1 / 10$ molar ratios) were measured upon $980 \mathrm{~nm}$ radiation laser excitation. The two emission spectra, shown in Fig. 6, are similar, and several bands due to both $\mathrm{Er}^{3+}$ and $\mathrm{Tm}^{3+}$ ions are visible. For the $1 / 1 / 10$ doped sample the red emission (around $650 \mathrm{~nm}$ ), mainly due to the ${ }^{4} \mathrm{~F}_{9 / 2} \rightarrow{ }^{4} \mathrm{I}_{15 / 2}$ transition of the $\mathrm{Er}^{3+}$ ions, is stronger than the green one. However, the NIR emission at $800 \mathrm{~nm}$, due to both the ${ }^{1} \mathrm{G}_{4} \rightarrow{ }^{3} \mathrm{H}_{5}$ and ${ }^{3} \mathrm{H}_{4} \rightarrow{ }^{3} \mathrm{H}_{6}$ transitions of the $\mathrm{Tm}^{3+}$ ions, is the strongest band of the spectrum. We point out that the bands clearly show the Stark structure and therefore they are poorly affected by inhomogeneous broadening, due a low amount of local disorder around the lanthanide ions, as already underlined for the doubly doped samples (see above). The observed UC spectra are similar than those observed for a nanocrystalline lutetium gallium garnet sample doped with $\mathrm{Er}^{3+} / \mathrm{Tm}^{3+} / \mathrm{Yb}^{3+}$ [35]. In Fig. 7 a schematic representation of the UC processes is shown. For the $1 / 1 / 10$ sample, for the reasons mentioned for the $1 / 10$ samples, since the $\mathrm{Yb}^{3+}$ concentration is relatively high with respect to both the $\mathrm{Er}^{3+}$ and $\mathrm{Tm}^{3+}$ ones, it is reasonable to state that the most probable UC process is via energy transfer (ET) from the $\mathrm{Yb}^{3+}$ ions to the $\mathrm{Er}^{3+}$ and $\mathrm{Tm}^{3+}$ ions, as shown in Fig. 7. Upon

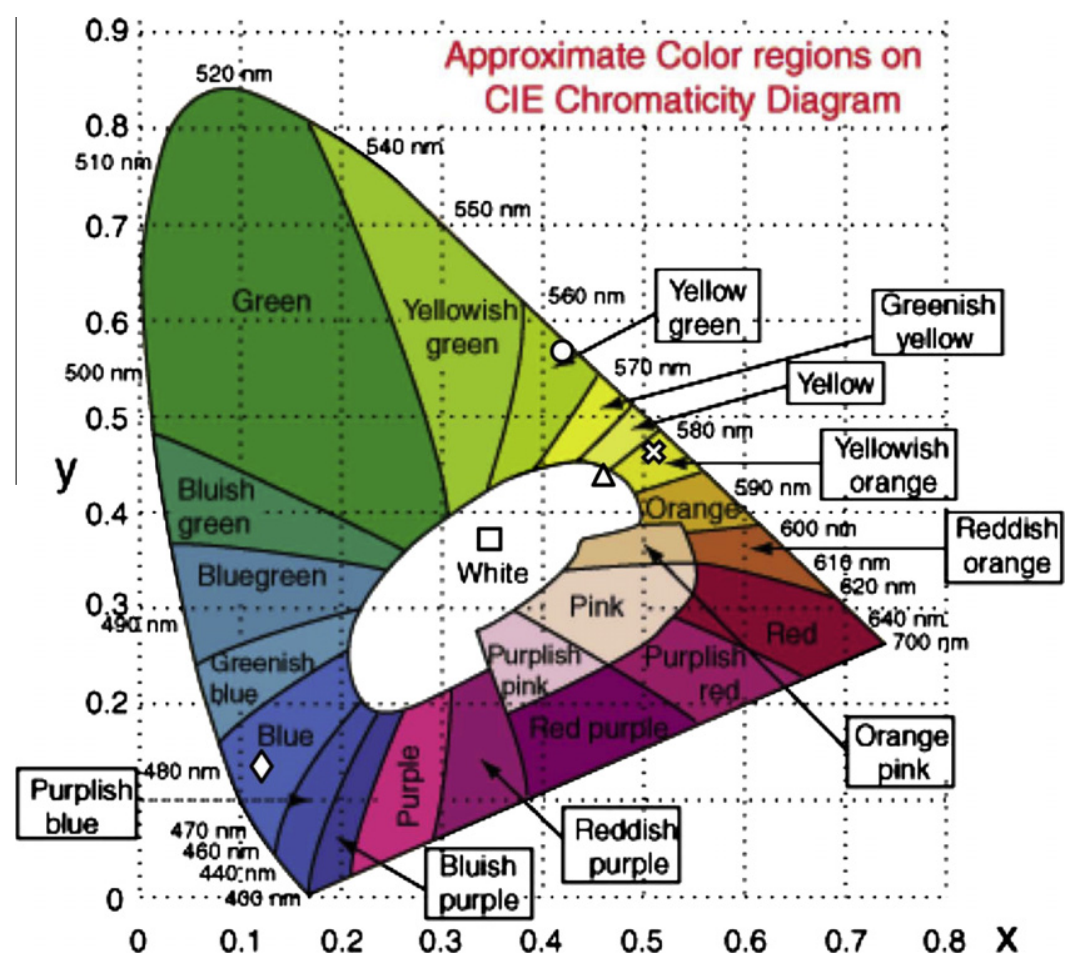

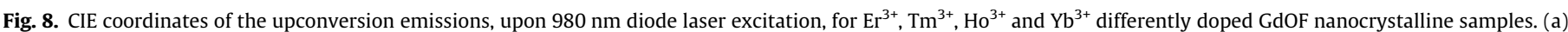

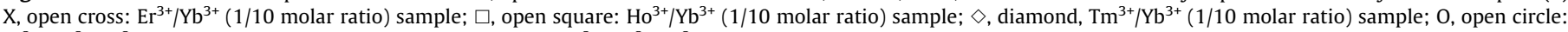
$\mathrm{Er}^{3+} / \mathrm{Tm}^{3+} / \mathrm{Yb}^{3+}(1 / 1 / 1)$ molar ratio sample; $\Delta$, open triangle: $\mathrm{Er}^{3+} / \mathrm{Tm}^{3+} / \mathrm{Yb}^{3+}(1 / 1 / 10)$ molar ratio sample. 
excitation at $980 \mathrm{~nm}$, one $\mathrm{Yb}^{3+}$ ion absorbs one photon and, by energy transfer, the excited states of both the $\mathrm{Er}^{3+}$ and $\mathrm{Tm}^{3+}$ ions are populated. Briefly, the $\mathrm{Er}^{3+}$ ion is excited to the ${ }^{4} \mathrm{I}_{11 / 2}$ level and subsequently to the ${ }^{4} \mathrm{~F}_{7 / 2}$ level. By MPR relaxation the ${ }^{2} \mathrm{H}_{11 / 2},{ }^{4} \mathrm{~S}_{3 / 2}$ and ${ }^{4} \mathrm{~F}_{9 / 2}$ levels are populated, and emission to lower lying excited levels occur (see Fig. 6). Furthermore, after the initial $\mathrm{Yb}^{3+} \rightarrow \mathrm{Tm}^{3+}$ energy transfer process, the $\mathrm{Tm}^{3+}$ ion is excited from the ${ }^{3} \mathrm{H}_{6}$ ground state to the ${ }^{3} \mathrm{H}_{5}$ level and then it relaxes by MPR processes to the ${ }^{3} \mathrm{~F}_{4}$ level. A second $\mathrm{Yb}^{3+} \rightarrow \mathrm{Tm}^{3+}$ ET process populates the ${ }^{3} \mathrm{~F}_{2}$ level of the $\mathrm{Tm}^{3+}$ ion, which subsequently decays to the ${ }^{3} \mathrm{H}_{4}$ one through non-radiative processes. The ${ }^{3} \mathrm{H}_{4}$ level then radiatively decays to the ${ }^{3} \mathrm{H}_{6}$ ground state emitting $800 \mathrm{~nm}$ photons. A third $\mathrm{Yb}^{3+} \rightarrow \mathrm{Tm}^{3+}$ (ET) process can also excite the $\mathrm{Tm}^{3+}$ ion from the ${ }^{3} \mathrm{H}_{4}$ to the ${ }^{1} \mathrm{G}_{4}$ level, which decays to lower lying states, generating emissions in the visible (at 480 and $650 \mathrm{~nm}$ ) and NIR (around $800 \mathrm{~nm}$ ) regions (see Fig. 6). In the 1/ $1 / 1$ triply doped sample, the $\mathrm{Yb}^{3+}$ ions have a much lower concentration ( $1 \mathrm{~mol} \%$ as for the $\mathrm{Er}^{3+}$ and $\mathrm{Tm}^{3+}$ ions) and therefore an excited state absorption (ESA) UC mechanism could be also present, contributing to the UC emission [36].

An investigation on the relative contribution of the ETU and ESA processes could be clarified by a detailed study of the excited state dynamics, which lies beyond the scope of this paper.

A CIE (Commission Internationale de l'éclairage) analysis [37] has been carried out for all the prepared nanocrystalline samples. The $(x, y)$ CIE coordinates have been calculated from the UC spectra, which were corrected for the detector response, multiplying the spectrum by each of the three color matching functions, after a proper normalization. The CIE coordinates are: $(0.51,0.47)$, $(0.34,0.37)$ and $(0.12,0.13)$ for the $\mathrm{Er}^{3+} / \mathrm{Yb}^{3+}, \mathrm{Ho}^{3+} / \mathrm{Yb}^{3+}$ and $\mathrm{Tm}^{3+} / \mathrm{Yb}^{3+}$ codoped samples, while are $(0.41,0.57)$ and $(0.47,0.44)$ for the $1 / 1 / 1$ and $1 / 1 / 10 \mathrm{Er}^{3+} / \mathrm{Tm}^{3+} / \mathrm{Yb}^{3+}$ triply doped samples, respectively, and are shown in Fig. 8 . It can be noted that the CIE coordinates for the codoped $\mathrm{Ho}^{3+} / \mathrm{Yb}^{3+}$ sample fall in the white region of the diagram, while the 1/1/10 triply doped $\mathrm{Er}^{3+} /$ $\mathrm{Tm}^{3+} / \mathrm{Yb}^{3+}$ sample lies at the border between the white and the yellow region of the diagram. Differently, the CIE coordinates for the $\mathrm{Tm}^{3+} / \mathrm{Yb}^{3+}$ and the $1 / 1 / 1 \mathrm{Er}^{3+} / \mathrm{Tm}^{3+} / \mathrm{Yb}^{3+}$ doped samples fall in the blue and yellow-green regions, respectively. It is therefore evident that a judicious choice of dopant lanthanide combination and molar ratios for the present GdOF nanocrystalline samples, permit to tune the color of the UC emission across the visible range, and even concentrate all the UC emission in the NIR range, as desired.

\section{Conclusions}

Nanocrystalline gadolinium fluoride samples codoped with $\mathrm{Er}^{3+} / \mathrm{Yb}^{3+}, \mathrm{Tm}^{3+} / \mathrm{Yb}^{3+}, \mathrm{Ho}^{3+} / \mathrm{Yb}^{3+}$ and triply doped with $\mathrm{Er}^{3+} / \mathrm{Tm}^{3+} /$ $\mathrm{Yb}^{3+}$ ions in several molar ratios have been prepared by a simple coprecipitation technique. A Rietveld refinement of the XRPD patterns revealed that all the samples are single phase with trigonal structure and GdOF stoichiometry, pointing out that only one regular site for the lanthanide ions is present in the lattice structure. It must be underlined that the $\mathrm{Tm}^{3+} / \mathrm{Yb}^{3+}$ doped sample shows a strong NIR-to-NIR upconversion in the $800 \mathrm{~nm}$ region upon $980 \mathrm{~nm}$ laser excitation. Moreover, we demonstrated that the present GdOF nanocrystalline hosts show UC emission of different colors and, with a proper choice of dopant lanthanide combination and molar ratios, this emission can be tuned across the visible range, and even concentrate all the UC emission in the NIR range, as desired, as evidenced by the CIE color coordinates of the differently doped GdOF nanocrystalline samples. As a conclusion, these materials are promising candidates that could be considered as NIR-to-visible and NIR-to-NIR upconverters, for instance in biomedical applications.

\section{Acknowledgement}

Fondazione Cariverona (Verona, Italy) is gratefully acknowledged for financial support.

\section{References}

[1] L. Armelao, S. Quici, F. Barigelletti, G. Accorsi, G. Bottaro, M. Cavazzini, E. Tondello, Coord. Chem. Rev. 254 (2010) 487.

[2] D. Solis, E. De la Rosa, O. Meza, L.A. Diaz-Torres, P. salas, C. Angeles-Chavez, J. Appl. Phys. 108 (2010) 023103.

[3] R. Reisfeld, J. Legendziewicz, M. Puchalska, T. Saraidarov, Opt. Mater. 26 (2004) 191.

[4] V. Bachmann, C. Ronda, A. Meijerink, Chem. Mater. 21 (2009) 2077.

[5] B.M. van der Ende, L. Aarts, A. Meijerink, Phys. Chem. Chem. Phys. 11 (2009) 11081.

[6] R. Reisfeld, Opt. Mater. 32 (2010) 850.

[7] F. Vetrone, J.A. Capobianco, Int. J. Nanotechnol. 5 (2008) 1306.

[8] L.M. Maestro, E. Martín Rodriguez, F. Vetrone, R. Naccache, H. Loro Ramirez, D. Jaque, J.A. Capobianco, J. García Solé, Opt. Express 18 (2010) 23544.

[9] X.F. Yang, X.T. Dong, J.X. Wang, G.X. Liu, Prog. Chem. 21 (2009) 1179.

[10] G. Blasse, B. Grabmaier, Luminescent Materials, Springer-Verlag, Berlin, 1994.

[11] S. Mishra, S. Daniele, G. Ledoux, E. Jeanneau, M.F. Joubert, Chem. Commun. 46 (2010) 3756.

[12] J. Hölsä, E. Kestilä, J. Alloys Compd. 225 (1995) 89.

[13] E. Antic-Fidancev, J. Hölsä, J.-C. Krupa, M. Lastusaari, J. Alloys Compd. 380 (2004) 303.

[14] L. Armelao, G. Bottaro, G. Bruno, M. Losurdo, M. Pascolini, E. Soini, E. Tondello, J. Phys. Chem. C 112 (2008) 14508.

[15] S. Fujihara, S. Koji, T. Kimura, J. Mater. Chem. 14 (2004) 1331

[16] Y.P. Du, Y.W. Zhang, L.D. Sun, C.H. Yan, J. Phys. Chem. C 112 (2008) 405.

[17] T. Passuello, F. Piccinelli, M. Pedroni, M. Bettinelli, F. Mangiarini, R. Naccache, F. Vetrone, J.A. Capobianco, A. Speghini, Opt. Mater. 33 (2011) 643.

[18] P.W. Young, The Rietveld Method, Oxford University Press, Oxford, 1993.

[19] MAUD computer program, L. Lutterotti, S. Gialanella, Acta Materialia 46 (1997) 101-110.

[20] J. Hölsa, E. Sailynoja, P. Ylha, P. Porcher, P. Deren, W. Strek, J. Phys. Chem. 100 (1996) 14736.

[21] R.D. Shannon, C.T. Prewitt, Acta Cryst. B 26 (1976) 1046.

[22] S.A. Wade, S.F. Collins, G.W. Baxter, J. Appl. Phys. 94 (2003) 84743.

[23] V.K. Tikhomirov, K. Driesen, V.D. Rodriguez, P. Gredin, M. Mortier, V.V. Moshchalkov, Opt. Express 17 (2009) 11794.

[24] F. Vetrone, R. Naccache, A. Zamarrón, A. Juarranz de la Fuente, F. SanzRodríguez, L. Martinez Maestro, E. Martín Rodriguez, D. Jaque, José García Solé, J.A. Capobianco, ACS Nano 4 (2010) 3254

[25] S. Chandra, F.L. Deepak, J.B. Gruber, D.K. Sardar, J. Phys. Chem. C 114 (2010) 874.

[26] J. Yang, C. Zhang, C. Peng, C. Li, L. Wang, R. Chai, J. Lin, Chem. Eur. J. 15 (2009) 4649 .

[27] F. Mangiarini, R. Naccache, A. Speghini, M. Bettinelli, F. Vetrone, J.A. Capobianco, Mater. Res. Bull. 45 (2010) 927.

[28] V. Venkatramu, M. Giarola, G. Mariotto, S. Enzo, S. Polizzi, C.K. Jayasankar, F. Piccinelli, M. Bettinelli, A. Speghini, Nanotechnology 21 (2010) 175703.

[29] F. Auzel, J. Lumin. 45 (1990) 341.

[30] G. Glaspell, J. Anderson, J.R. Wilkins, M. Samy El-Shall, J. Phys. Chem. C 112 (2008) 11527.

[31] J. Yang, J. Lin, J. Electrochem. Soc. 157 (2010) K273.

[32] G. Chen, T.Y. Ohulchanskyy, R. Kumar, H. Ågren, P.N. Prasad, ACS Nano 4 (2010) 3163.

[33] M. Nyk, R. Kumar, T.Y. Ohulchanskyy, E.J. Bergey, P.N. Prasad, Nano Lett 8 (2008) 3834.

[34] H.T. Wong, H.L.W. Chan, J. Hao, Opt. Express 18 (2010) 6123.

[35] V. Mahalingam, F. Mangiarini, F. Vetrone, V. Venkatramu, M. Bettinelli, A. Speghini, J.A. Capobianco, J. Phys. Chem. C 112 (2008) 17745.

[36] F. Auzel, Chem. Rev. 104 (2004) 139.

[37] G. Wyszecki, W.S. Stiles, Color science. concepts and methods, quantitative data and formulae, John Wiley and Sons Inc., New York, 1982. 